\title{
PENGEMBANGAN SELF-HELP BOOK DENGAN PROGRAM MAKING FRIENDS WITH YOURSELF UNTUK MENINGKATKAN SELF-COMPASSION PESERTA DIDIK KELAS X SMA NEGERI 38 JAKARTA
}

\author{
Brilliyana Kartika Sari Dewi ${ }^{1}$ \\ Wening Cahyawulan ${ }^{2}$
}

\begin{abstract}
Abstrak
Penelitian ini dilakukan untuk mengembangkan self-help book dengan program making friends with yourself untuk meningkatkan self-compassion peserta didik kelas X SMA Negeri 38 Jakarta. Metode penelitian yang digunakan dalam penelitian ini adalah DBR yang merupakan akronim dari Design Based Research atau biasa disebut Educational Design Research yang terdiri dari tiga tahapan inti yakni (1) Analisis dan Eksplorasi, (2) Desain dan Konstruk, (3) Evaluasi dan Refleksi. Penelitian ini hanya dilakukan sampai tahap evaluasi. Penelitian dilakukan di SMA Negeri 38 Jakarta. Subjek penelitian ini adalah 154 peserta didik kelas X SMA Negeri 38 Jakarta. Dalam mengumpulkan data, peneliti menggunakan teknik penyebaran angket dan wawancara pada peserta didik. Hasil uji validasi dengan ahli media, skor yang didapatkan sebesar $77,27 \%$ (layak) dengan keunggulan memiliki desain yang menarik, pemilihan ukuran dan bentuk yang tepat, serta tujuan materi dapat tersampaikan. Sedangkan hasil uji validasi dengan ahli materi mendapatkan skor sebesar $91,25 \%$ (sangat layak) yang artinya self-help book yang dikembangkan telah sesuai dengan program making friends with yourself. Pengembangan self-help book memberikan informasi mengenai self-compassion, serta keterampilan dalam mengembangkan self-compassion.
\end{abstract}

Kata Kunci: Self-Help Book, Self-Compassion.

\begin{abstract}
This research was conducted to develop a self-help book with making friends with yourself program to improve the self-compassion of class $X$ students of 38 Senior High School. The research method used in this research is DBR which is an acronym for Design Based Research or commonly called Educational Design Research which consists of three core stages, (1) Analysis and Exploration, (2) Design and Construct, (3) Evaluation and Reflection. This research was only conducted until the evaluation stage. The research was conducted at 38 Senior High School. The subjects of this study were 154 students of class X 38 Senior High School. In collecting data, researchers used questionnaire distribution techniques and interviews with students. The results of the validation test with media experts, the score obtained was $77.27 \%$ (feasible) with the advantage of having an attractive design, selecting the right size and shape, and conveying the objectives
\end{abstract}

\footnotetext{
${ }^{1}$ Universitas Negeri Jakarta, brilliyanakartikasaridewi_1715161510@mhs.unj.ac.id

${ }^{2}$ Universitas Negeri Jakarta,wening@unj.ac.id
} 
of the material. While the results of the validation test with material experts get a score of $91.25 \%$ (very feasible), which means that the self-help book developed is in accordance with the making friends with yourself program. The development of the self-help book provides information about self-compassion, as well as skills in developing self-compassion.

Keywords: Self-Help Book, Self-Compassion.

\section{PENDAHULUAN}

Masa remaja bisa juga disebut sebagai masa transisi dari anak-anak menuju dewasa. Santrock (2016) mengatakan bahwa remaja berada pada rentang usia 1019 tahun. Masa remaja merupakan masa yang penting dalam kehidupan. Kusuma dan Suwarti (2015) mengatakan bahwa beberapa perubahan yang dialami selama masa transisi antara masa anak-anak menuju masa dewasa yang dialami meliputi perubahan biologis, kognitif, dan sosial emosional.

Neff (2003) mengemukakan bahwa self-compassion merupakan rasa belas kasih pada diri ketika mengalami keadaan yang sulit, memaafkan diri ketika melakukan kesalahan atau kegagalan, serta memberikan penghargaan atas segala yang telah diperbuat dengan cara menghargai diri sendiri. Self-compassion memiliki tiga elemen yaitu self-kindness vs selfjudgement, common humanity vs isolation, dan mindfulness vs over-identified.

Menurut Neff (2015) individu yang memiliki self-compassion tinggi dapat dilihat dengan mampu untuk menerima segala kelebihan dan kekurangan diri sendiri, menerima kegagalan dan mengganggap bahwa hal tersebut biasa dialami oleh manusia lainnya, menyadari bahwa sesama manusia saling membutuhkan. Sedangkan individu yang memiliki self-compassion rendah dapat dilihat melalui sering menyalahkan diri sendiri, takut dan selalu cemas untuk menghadapi kegagalan, hingga pesimis dalam memandang masa depan.

Self-compassion memiliki peran penting untuk remaja karena dapat membantu remaja dalam mengatasi masalah yang dialami di dalam kehidupannya. Selfcompassion memiliki peran untuk menjaga diri remaja dari kritik diri yang berlebih. Menurut Repi (2019) self-compassion tidak menjamin individu akan terhindar dari kritikan namun self-compassion membantu remaja untuk membentuk emosi yang positif, sehingga individu tidak akan mengalami keterpurukan yang mendalam setelah mendapatkan kritik dari orang disekitarnya.

Upaya yang dapat dilakukan untuk meningkatkan self-compassion pada peserta didik dapat diwujudkan secara mandiri melalui self-help book. Menurut Norcoss dalam Campbell \& Smith (2003) praktik psikologi merekomendasikan kegiatan selfhelp merujuk kepada self-help book (85\%), self-help groups (82\%), films (46\%), Web sites (34\%), dan autobiographies (24\%). Hal tersebut memperlihatkan bahwa selfhelp book memiliki peran lebih besar dibandingkan dengan yang lain.

Bergsma dalam Bergsma (2008) selfhelp book merupakan media yang digunakan untuk mengatasi permasalahan yang dialami oleh individu tanpa memerlukan tenaga professional. Oleh karena itu semua buku yang dapat mewujudkan tujaun praktis ini dianggap self-help book. Studi pendahuluan di SMA Negeri 38 Jakarta menggunakan selfcompassion scale (SCS) yang telah diadaptasi, dengan jumlah responden sebanyak 154 orang siswa kelas $\mathrm{X}$ menunjukkan sebesar $30,07 \%$ berada pada kategori tinggi, $65,36 \%$ berada pada kategori sedang, dan $4,58 \%$ berada pada kategori rendah. Hal tersebut menunjukkan bahwa self-compassion pada siswa kelas $\mathrm{X}$ SMA Negeri 38 Jakarta berada pada kategori sedang. 
Berdasarkan hasil studi pendahuluan dan wawancara yang dilakukan dengan peserta didik sebanyak $86,36 \%$ dari 154 peserta didik tertarik untuk membaca selfhelp book, kemudian 82,47\% dari 154 peserta didik belum pernah membaca selfhelp book. Peserta didik tertarik dengan isu yang akan dibahas yakni mengenai selfcompassion, oleh karena itu peserta didik dapat menggunakan self-help book yang akan dikembangkan jika peserta didik memiliki minat untuk membaca. Selain itu peserta didik juga berharap agar pengembangan media self-help book dirancang dengan warna dan gambar yang menarik.

Berdasarkan wawancara yang dilakukan bersama peserta didik didapatkan bahwa peserta didik kelas $\mathrm{X}$ belum mendapatkan materi mengenai selfcompassion pada saat jam bimbingan klasikal. Berdasarkan data tersebut pengembangan self-help book akan berisi pengetahuan mengenai self-compassion, serta langkah-langkah untuk meningkatkan self-compassion yang akan disampaikan melalui visual yang menarik agar dapat diminati serta dipahami oleh para peserta didik.

Dengan begitu maka peneliti ingin membantu remaja untuk meningkatkan selfcompassion melalui media self-help book. dengan menggunakan program Making Friends with Yourself untuk peserta didik kelas X SMA Negeri 38 Jakarta. Program tersebut dipilih karena bertujuan untuk membantu remaja meningkatkan selfcompassion.

\section{Self-compassion}

Menurut Neff (2003) self-compassion dapat diartikan sebagai rasa belas kasih terhadap diri sendiri ketika mengalami suatu kesulitan atau penderitaan, memaafkan diri sendiri atas suatu kegagalan atau kesalahan yang diperbuat, serta lebih menghargai segala sesuatu yang telah diperbuat. Self-compassion cenderung meningkatkan rasa kasih sayang dan keperdulian terhadap orang lain. Selfcompassion cenderung membantu remaja untuk menghindari pikiran-pikiran negatif pada saat mengalami masalah, dan membantu seseorang agar tidak memikirkan permasalahan yang dialami secara berlarutlarut. Self-compassion terdiri dari tiga elemen yaitu self-kindness vs self-judgment, common humanity vs isolation, mindfulness vs over-identified.

Self-kindness merupakan kemampuan seseorang untuk memahami serta menerima diri dengan baik, tidak mengadili diri sendiri dan juga memberikan kritik terhadap diri sendiri. Sedangkan selfjudment menurut adalah suatu kondisi pada saat individu terlalu mengkritik diri sendiri atas penderitaan atau masalah yang dialaminya.

Common humanity merupakan kemampuan seseorang dalam memandang bahwa seseorang yang mengalami penderitaan, kegagalan, dan tantangan merupakan bagian dari kehidupan yang juga dialami oleh semua orang. Hal tersebut berkebalikan dengan isolation, seseorang yang merasa terisolasi maka akan merasa seakan hanya dirinya yang mengalami keadaan tertekan.

Mindfulness merupakan cara seseorang dalam menerima pemikiran serta perasaan yang dirasakan saat ini, sedangkan overidentified adalah individu yang mereaksi secara berlebihan pada saat mengalami penderitaan atau permasalahan, individu akan merasakan sakit tanpa alasan.

Terdapat beberapa faktor yang mempengaruhi self-compassion, yaitu: lingkungan keluarga, usia, jenis kelamin, budaya. Menurut Hasanah dan Hidayati (2016) self-compassion dapat membantu individu lebih mengenal dirinya sendiri, lebih menyayangi dirinya sendiri, sehingga akan mempermudah individu dalam menghadapi kesulitan yang sedang dialami. Self-compassion juga dapat menjadi penolong untuk lebih meringankan rasa terpuruk sehingga individu akan menjadi 
lebih terbuka pada kegagalan atau masalah yang dialaminya.

\section{Making Friends with Yourself (MFY)}

Bluth, Gaylord, Campo, Mullarkey, \& Hobbs (2015) Making Friends with Yourself (MFY) merupakan suatu program yang diadaptasi dari program Mindful Self Compassion (MSC). MFY merupakan program yang dibuat untuk remaja. Program MFY merupakan program yang mengajarkan seseorang untuk mengembangkan keterampilan yang dimiliki terkait dengan elemen yang ada pada self-compassion yaitu self-kindness, common humanity, dan mindfulness.

Program Making Friends with Yourself terdiri dari 8 sesi yaitu: (1) Menemukan mindful self-compassion,

Memperhatikan dengan sengaja, (3) Cinta kasih sayang, (4) self-compassion, (5) Selfesteem/self-compassion, (6) Hidup mendalam, (7) Bekerja dengan emosi yang berat, (8) Merangkul hidup Anda dengan rasa syukur.

\section{Self-Help Book}

Bergsma (Bergsma, 2008) self-help book merupakan media yang dapat digunakan untuk membantu mengatasi masalah pribadi atau emosional pada diri sendiri tanpa memerlukan bantuan professional. Menurut Anderson dalam Watkins \& Clum (2008) buku bantuan diri atau self-help book bertujuan untuk dapat membimbing dan mendorong klien untuk melakukan perubahan, sehingga meningkatkan manajemen diri, bukan hanya memberikan informasi saja.

Starker dalam Bergsma (2008) menyebutkan empat faktor pragmatis yang menjelaskan keberhasilan atau manfaat dari self-help book, yaitu: (1) Biaya yang dikeluarkan untuk self-help book lebih rendah dibandingkan harus berkonsultasi dengan seorang terapis, (2) Self-help book mudah untuk didapat dan dapat dibaca kapan saja, (3) Self-help book akan mengatasi masalah individu tanpa harus diketahui oleh umum atau harus dibicarakan dengan seorang terapis, (4) Self-help book memberikan kesempatan bagi pembacanya untuk menjadi bagian dalam dalam buku tersebut.

\section{METODE PENELITIAN}

Metode penelitian yang digunakan dalam penelitian ini adalah DBR yang merupakan akronim dari Design Based Research atau biasa disebut Educational Design Research. Design Based Research khususnya berkaitan dengan pengembangan seperti yang disebut Lagemann (McKenny \& Thomas, 2013) sebagai pengetahuan yang dapat digunakan, sehingga menghasilkan produk penelitian yang relevan untuk praktik pendidikan. Barab dan Squire (Herrington dkk., 2007) mendefinisikan Design Based Research sebagai serangkaian pendekatan, dengan maksud menghasilkan teori baru, artefak, dan praktik yang menjelaskan dan berpotensi berdampak pada pembelajaran dan pengajaran dalam pengaturan naturalistik.

Design Based Research memiliki beberapa proses inti menurut Mckenney \& Reeves (McKenny \& Thomas, 2013) yakni: (1) Analisis dan Eksplorasi, (2) Desain dan Konstruk, (3) Evaluasi dan Refleksi. Penelitian ini dilakukan di SMA Negeri 38 Jakarta dan waktu penelitian yang dilakukan pada bulan September 2019Agustus 2020. Uji coba produk pada penelitian ini melibatkan beberapa responden seperti ahli media, dan ahli materi untuk melihat kelayakan produk yang dikembangkan. Teknik pengumpulan data menggunakan kuesioner yang divalidasi secara internal oleh ahli. Namun, peneliti tidak melakukan uji pada peserta didik hal tersebut dikarenakan keadaan saat ini sedang pandemi Covid-19.

\section{HASIL PENELITIAN}

Penelitian ini dilakukan untuk mengembangkan media self-help book untuk meningkatkan self-compassion dengan menggunakan program making 
friends with yourself untuk peserta didik kelas X SMA Negeri 38 Jakarta. Dalam pengembangan media ini ada beberapa tahapan yang dilakukan yaitu, analisis dan eksplorasi, desain dan konstruksi, serta evaluasi. Penelitian ini hanya dilakukan sampai tahap evaluasi. Berdasarkan hasil penelitian yang telah dilakukan maka dapat dilihat sebagai berikut:

Tahap analisis dan eksplorasi, dimulai dengan melakukan diskusi bersama dengan ahli serta peneliti yang membahas mengenai self-compassion, self-help book, serta program making friends with yourself. Berikutnya peneliti melakukan kajian literature yakni dengan membaca serta memahami isi literature yang bertujuan untuk memberikan gagasan terkait dengan isu yang dikembangkan. Lalu, peneliti melakukan studi pendahuluan guna memperoleh data dan melihat kebutuhan peserta didik. Dalam melakukan penelitian, peneliti membangun jejaring dengan beberapa pihak.

Tahap desain dan konstruksi, dimulai dengan melakukan brainstorming bersama dengan ahli serta peneliti lainnya hingga menghasilkan ide-ide dalam pengembangan media. Ide-ide yang telah dituliskan kemudian dipertimbangkan menggunakan strategi strength/weakness. Berikutnya peneliti merancang media yang akan dikembangkan berdasarkan dengan hasil studi pendahuluan serta berdasarkan ide-ide yang telah di diskusikan seperti, penggunaan warna, ilustrasi, ukuran dan jenis tulisan, serta isi dalam self-help book yang akan dikembangkan. Lalu desain awal tersebut di supervisi oleh ahli sebelum dilakukan validasi oleh ahli media dan ahli materi.

Tahap evaluasi, yaitu peneliti melakukan validasi terhadap pengembangan media kepada ahli media dan ahli materi. Tahap ini diawali dengan menentukan metode spesifik. Berikutnya peneliti mencari instrument yang digunakan untuk diberikan kepada evaluator yang akan menilai media serta materi yang telah dikembangkan. Didapatkan hasil dari evaluator yaitu $77 \%$ (tabel 1) untuk media dengan kriteria layak, dan 91\% (tabel 2) untuk materi dengan kriteria sangat layak.

\begin{tabular}{clcc}
\hline No. & \multicolumn{1}{c}{ Dimensi } & $\%$ & Kriteria \\
\hline 1. & Desain & & \\
2. & Materi & & \\
3. & Bahasa & $77 \%$ & Layak \\
4. & Ilustrasi & & \\
5. & Tipografi & & \\
6. & Lay Out & \\
\hline & Tabel 1. Hasil Validasi Media
\end{tabular}

\begin{tabular}{clcc}
\hline No. & \multicolumn{1}{c}{ Dimensi } & $\%$ & Kriteria \\
\hline 1. & Isi Materi & & Sangat \\
2. & Bahasa & $91.25 \%$ & Layak \\
3. & Ilustrasi & & \\
\hline
\end{tabular}

Tabel 2. Hasil Validasi Materi

Berdasarkan saran dari evaluator media dan materi, maka perbaikan yang perlu dilakukan pada media yaitu penggunaan bahasa perlu diperbaiki agar tidak seperti bahasa terjemahan sehingga peneliti akan memperbaiki dengan menyesuaikan bahasa yang digunakan. Sedangkan bagian materi perlu diberikan kesimpulan pada tiap bab dalam buku, serta pada tiap-tiap bagian kurang memperlihatkan kaitan antara bagian yang satu dengan bagian berikutnya.

Penelitian ini tentunya memiliki beberapa keterbatasan sehingga masih harus diperbaiki agar dapat dipergunakan secara utuh oleh peserta didik dan guru BK. Beberapa keterbatasan dalam penelitian ini yaitu: (1) Penelitian ini terbatas hanya pada sampai pada pengujian alfa dan hanya pada sampai tahap evaluasi, (2) Media self-help book yang telah dibuat belum diimplementasikan kepada peserta didik, sehingga belum diketahui keefektivitasannya, (3) Pengujian terhadap media self-help book baru sampai pada uji ahli media dan materi, belum sampai pada uji ke peserta didik .

\section{KESIMPULAN}

Penelitian mengenai pengembangan self-help book untuk meingkatkan selfcompassion dengan menggunakan program making friends with yourself untuk peserta 
didik kelas X SMA Negeri 38 Jakarta. Penelitian dimulai melalui tahap studi pendahuluan untuk melihat tingkat selfcompassion peserta didik kelas $\mathrm{X}$ dan melihat kebutuhan peserta didik. Berdasarkan studi pendahuluan selfcompassion peserta didik kelas X di SMA Negeri 38 Jakarta berada pada kategori sedang. Selain itu data yang didapatkan melalui angket kebutuhan terkait self-help book yang dibuat, peserta didik berminat untuk membaca self-help book mengenai self-compassion dan berharap bahwa selfhelp book yang dibuat memiliki ilustrasi dan warna yang sesuai dengan kriteria peserta didik. Dengan begitu media selfhelp book dapat dikembangkan sesuai minat peserta didik SMA Negeri 38 Jakarta.

Metode penelitian yang dilakukan adalah Design Based Research. Penelitian ini hanya dikembangkan sampai pengujian alfa, dimana pengujian ini berfokus pada struktur internal desain tetapi pengujian ini juga memperdulikan fungsionalitas dari suatu desain. Terdapat dua hal yang dilakukan pada pengujian alfa yaitu kekuatan, dan kelayakan.

Self-help book ini telah melalui tahap evaluasi formatif yang dilakukan oleh ahli media, dan ahli materi. Dari evaluasi tersebut didapatkan hasil validitas media sebesar $77 \%$ berada pada kategrori layak dan hasil validitas materi sebesar $91.25 \%$. Hasil evaluasi tersebut termasuk pada kategori sangat layak.

Keunggulan media self-help book yang telah dikembangkan ialah memiliki desain yang menarik, pemilihan ukuran dan bentuk yang tepat, serta tujuan materi dapat tersampaikan. Kekurangannya ialah penggunaan bahasa masih kurang mengikuti karakteristik peserta didik.

Berdasarkan kesimpulan diatas, maka terdapat beberapa saran dari peneliti sebagai berikut: Penelitian ini terbatas hanya sampai tahapan evaluasi, sehingga peneliti berikutnya dapat melanjutkan hingga tahap refleksi, Penelitian ini terbatas hanya sampai pada uji keterbacaan, sehingga peneliti lain dapat melanjutkan dengan melakukan uji ketercapaian tujuan, Media self-help book ini belum di uji ke efektivitasnya, sehingga peneliti lain dapat melanjutkannya untuk mencapai pada uji ke efektivitasnya.

\section{DAFTAR PUSTAKA}

Bergsma, A. (2008). Do self-help books help? Journal of Happiness Studies, 9(3), 341-360. https://doi.org/10.1007/s10902-0069041-2

Bluth, K., Gaylord, S. A., Campo, R. A., Mullarkey, M. C., \& Hobbs, L. (2015). Making friends with yourself: a mixed methods pilot study of a mindful self-compassion program for adolescents. Mindfulness, 7(2), 479492. https://doi.org/10.1007/s12671015-0476-6

Campbell, L. F., \& Smith, T. P. (2003). Integrating self-help books into psychotherapy. Journal of Clinical Psychology, 59(2), 177-186. https://doi.org/10.1002/jclp.10140

Hasanah, F., \& Hidayati, F. (2016). Hubungan antara self-compassion dengan alienasi pada remaja (sebuah studi korelasi pada siswa SMK negeri 1 majalengka). Empati, 5(4), 750-756.

Herrington, J., McKenney, S., Reeves, T., \& Oliver, R. (2007). Design-based research and doctoral students: Guidelines for preparing a dissertation proposal. Research Online, 1(1), 110.

https://doi.org/10.1017/CBO97811074 15324.004

Kusuma, S. W., \& Suwarti. (2015). Relationship between emotional stability with school. Psycho Idea, 13(2), 39-46.

McKenny, S., \& Thomas, R. C. (2013). Conducting educational design research. In Educational Media International (Vol. 50, Nomor 3). Routledge. https://doi.org/10.1080/09523987.201 3.843832 
Neff, K. (2003). Self and identity selfcompassion: an alternative conceptualization of a healthy attitude toward oneself self-compassion: an alternative conceptualization of a healthy attitude toward oneself. Psychology, November 2012, 37-41. https://doi.org/10.1080/152988603901 29863

Neff, K. (2015). The self-compassion scale is a valid and theoretically coherent measure of self-compassion. Mindfulness, 7(1), 264-274. https://doi.org/10.1007/s12671-015-
0479-3

Repi, A. A. (2019). Self compassion versus self esteem terhadap pembentukan self-concept remaja: mana yang lebih baik? Jurnal Psikologi, 4(2), 1-11.

Santrock, J. W. (2016). Adolescence sixteenth edition (Sexteenth). United States of America: Mc Graw Hill Education.

Watkins, P. Lou, \& Clum, G. A. (2008). Handbook of self-help therapies (W. P. Lou \& G. A. Clum (ed.)). Newyork: Routledge. 


\section{LAMPIRAN}

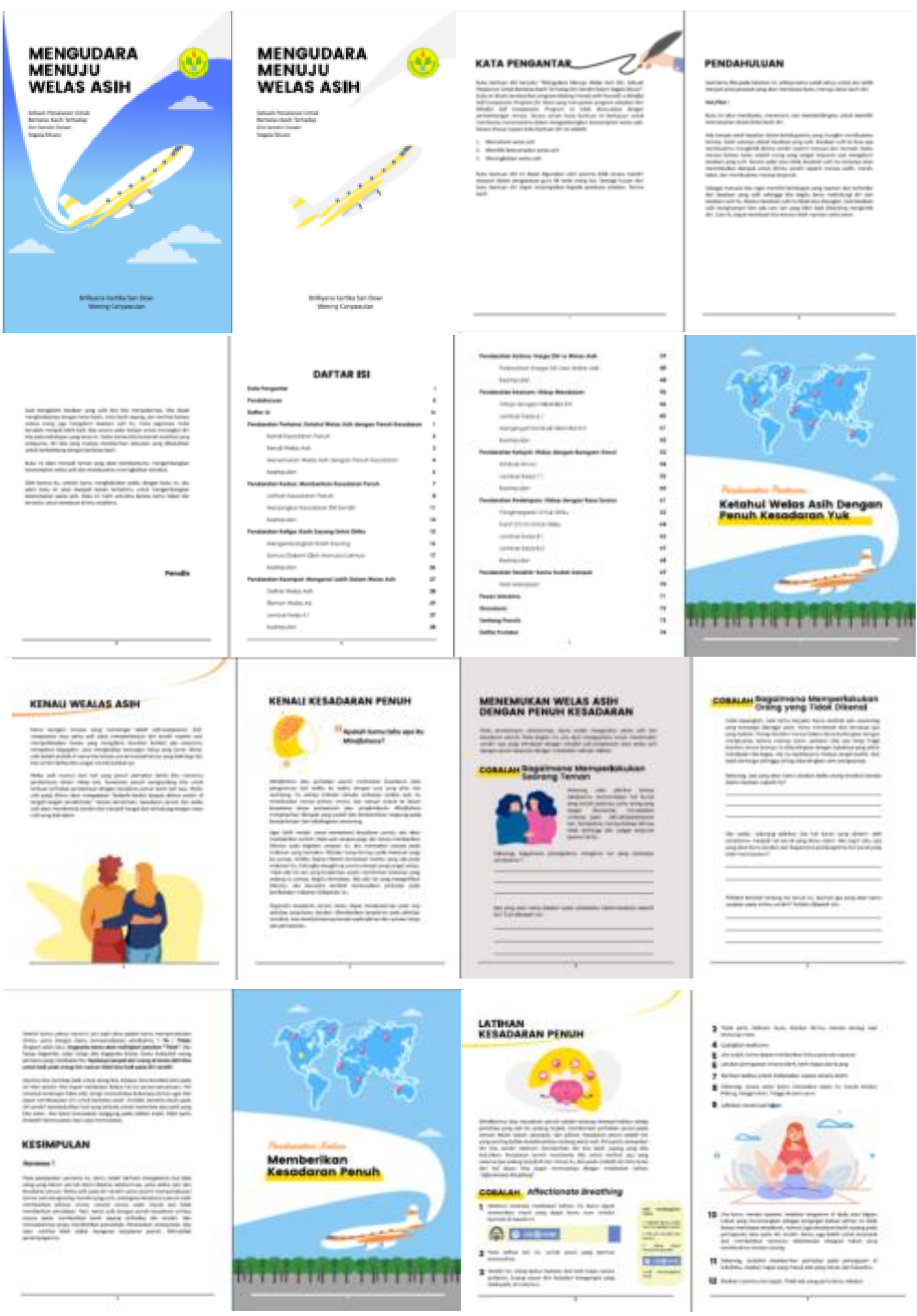




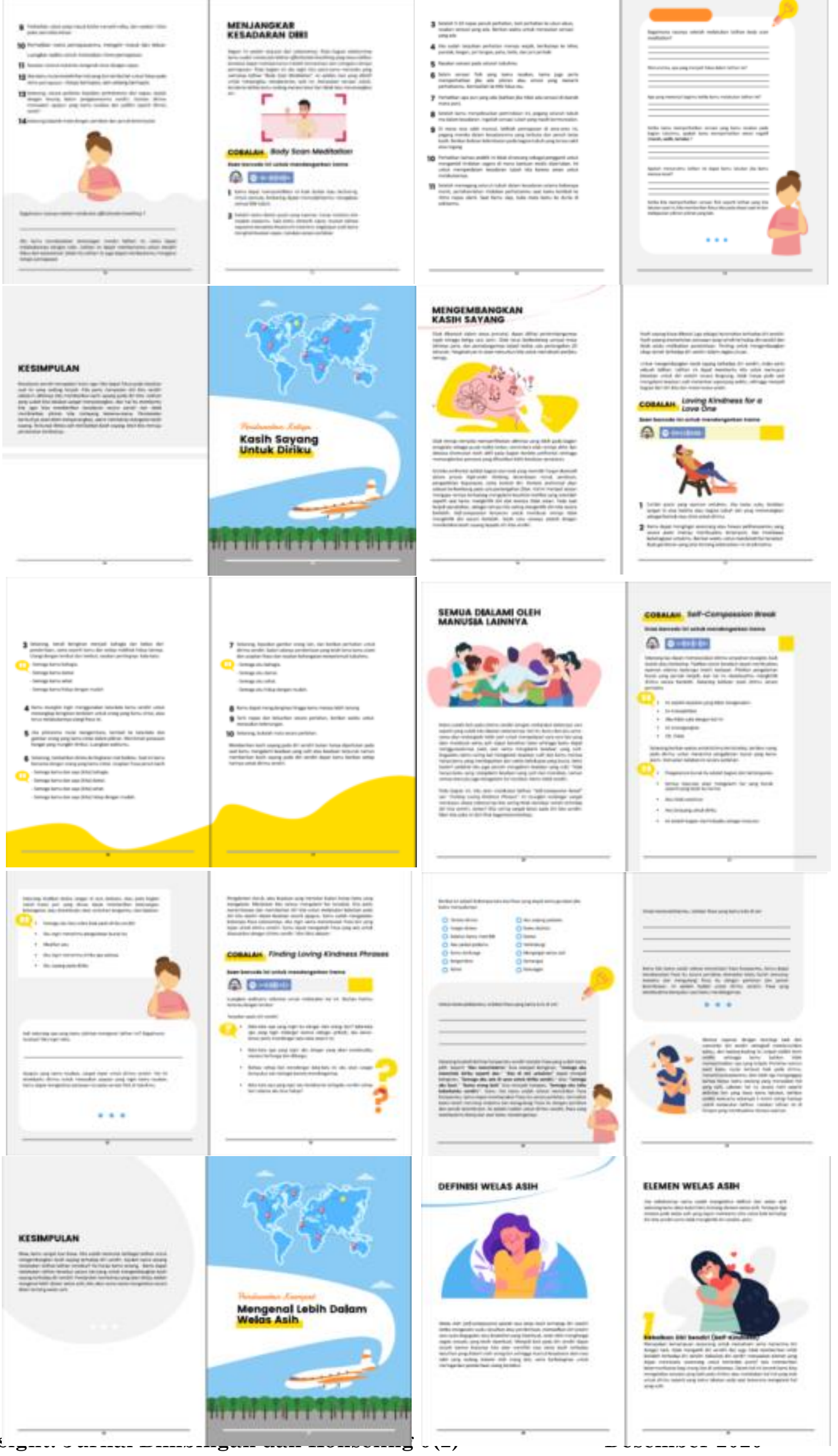




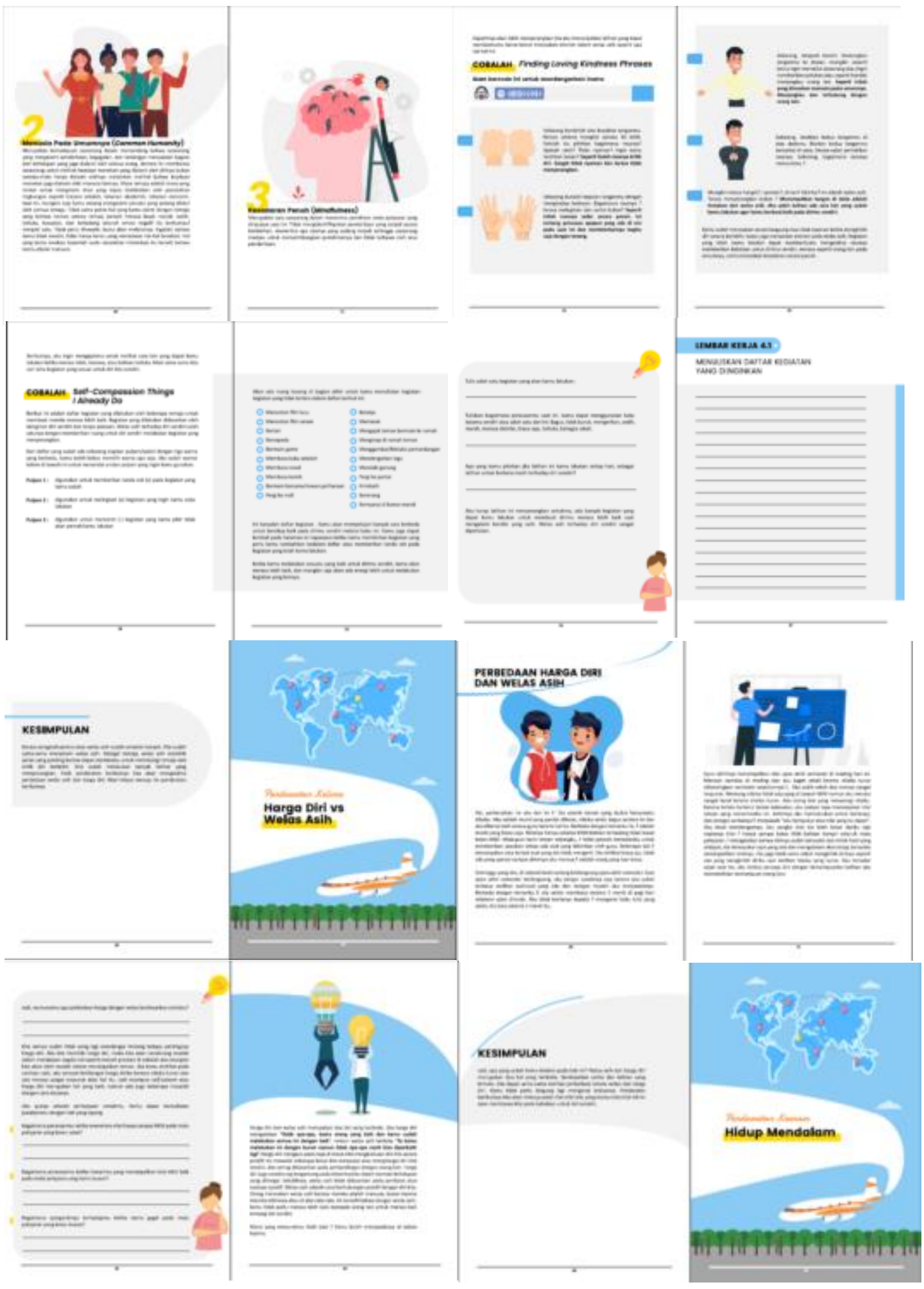




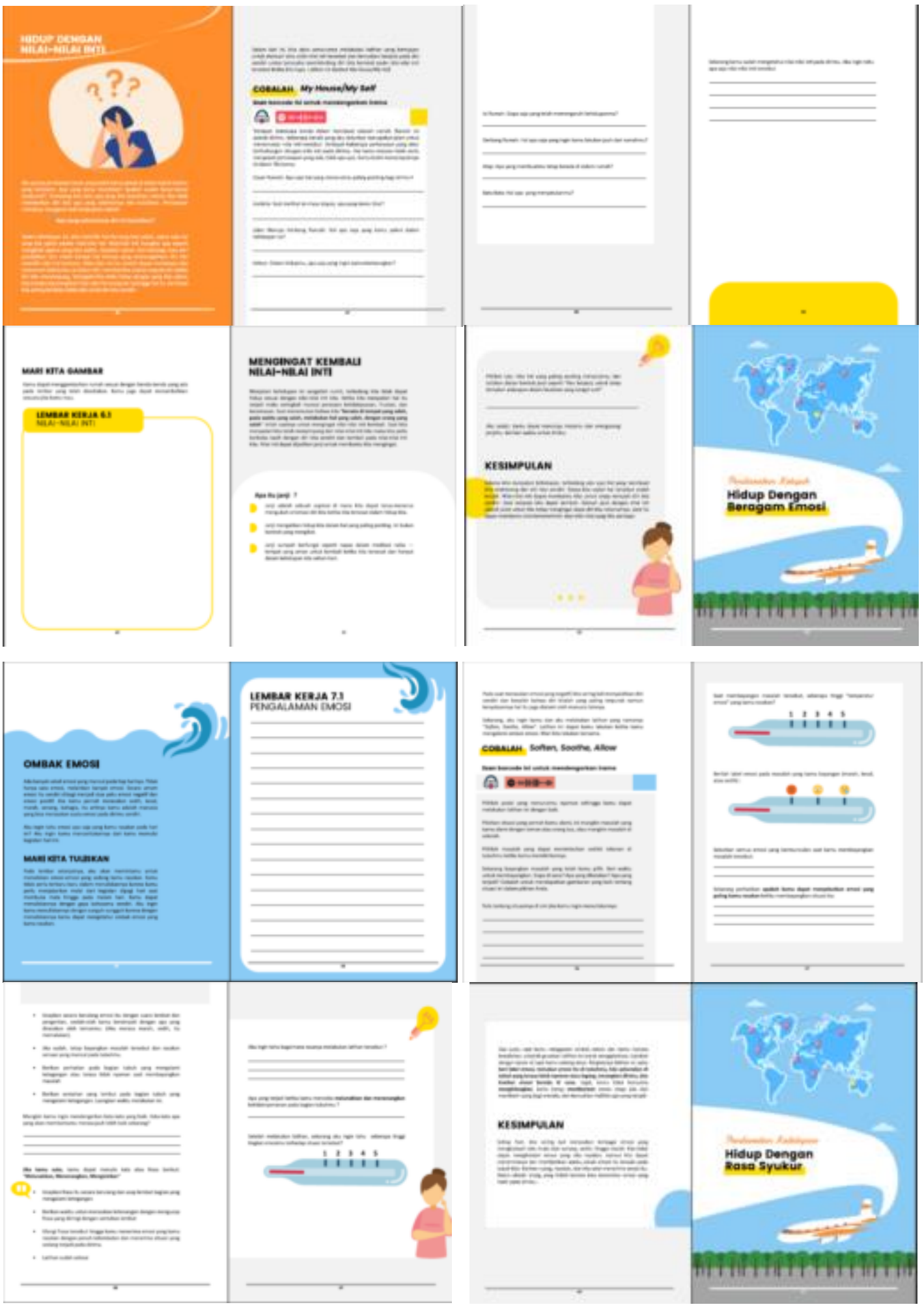




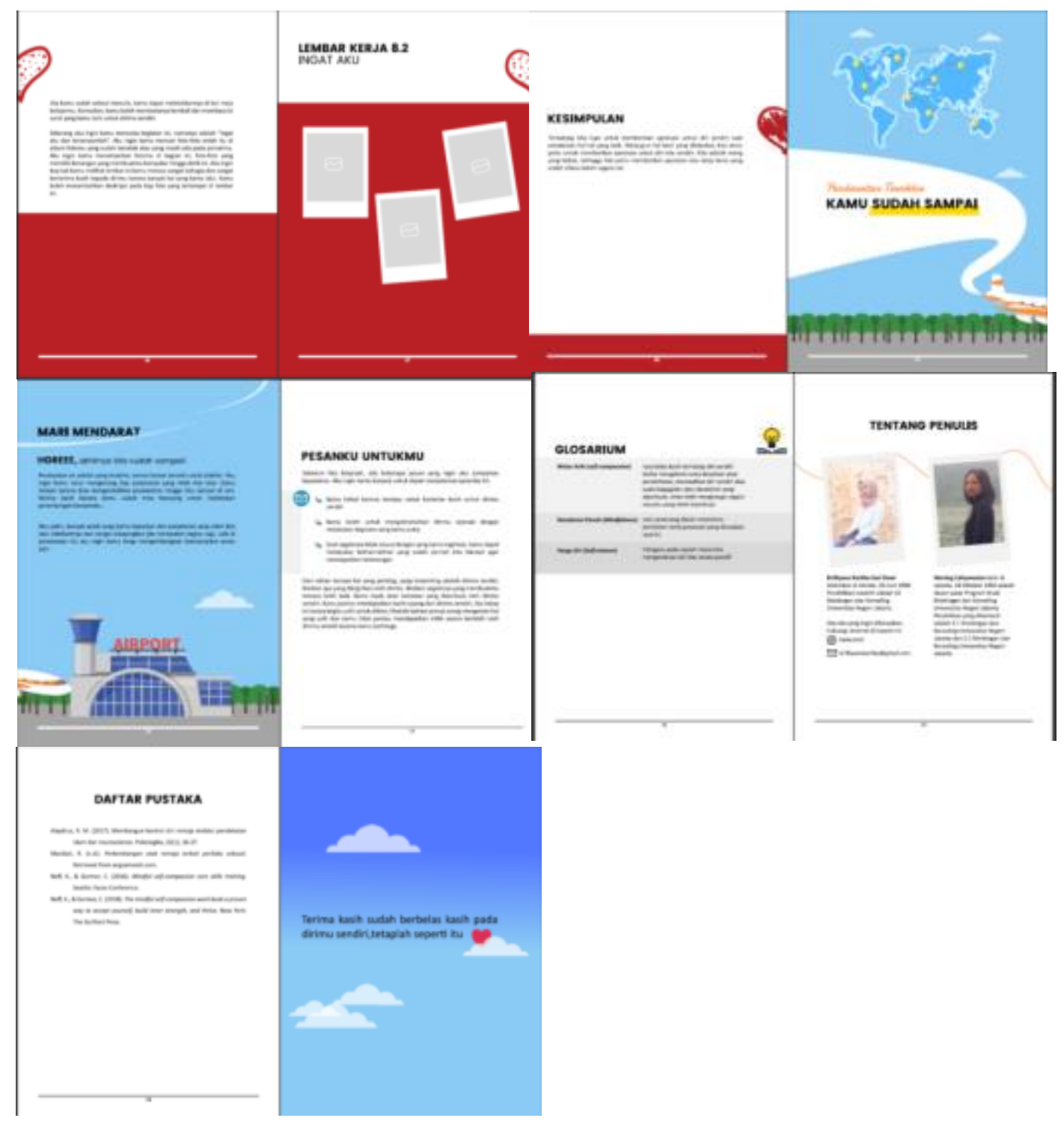

